\title{
PELATIHAN PEMBUATAN MEDIA TANAM DI DESA KARANGSARI KECAMATAN DARMA KABUPATEN KUNINGAN JAWA BARAT
}

\author{
Yayan Hendrayana ${ }^{1} *$, Agus Yadi Ismail ${ }^{2}$, Nina Herlina ${ }^{3}$ \\ ${ }^{1,2}$ Prodi Kehutanan Fakultas Kehutanan Universitas Kuningan \\ ${ }^{2}$ Prodi IImu Lingkungan Fakultas Kehutanan Universitas Kuningan \\ *yayan.hendrayana@uniku.ac.id
}

\begin{abstract}
Planting media is an important part of the process of making seeds in the nursery. A good planting medium must meet the requirements of not containing seeds of pests and diseases, free of weeds, capable of holding water, but also capable of removing or draining excess water, crumbs and porous so that roots can grow and develop. The purpose of this community empowerment activity is to introduce and manufacture planting media for making nurseries. Implementation of activities in Karangsari Village, Darma District, Kuningan Regency. The result of this activity was that 20 members of the community group participated. The types of planting media around Karangsari Village are soil, ferns, compost, and humus. By knowing how to make good planting media, the community groups involved will have knowledge and will independently provide planting media for the purpose of procuring seeds or for trading.
\end{abstract}

Keywords: seeds; empowerment; counseling; nursery

\begin{abstract}
Abstrak
Media tanam merupakan salah satu bagian penting dari proses pembuatan bibit di persemaian. Media tanam yang baik harus memenuhi persyaratan tidak mengandung bibit hama dan penyakit, bebas gulma, mampu menampung air, tetapi juga mampu membuang atau mengalirkan kelebihan air, remah dan porous sehingga akar bisa tumbuh dan berkembang. Tujuan kegiatan pengabdian kepada masyarakat ini berupa pengenalan dan pembuatan media tanam untuk pembuatan persemaian. Pelaksanaan kegiatan di Desa Karangsari Kecamatan Darma Kabupaten Kuningan. Hasil kegiatan ini adalah diikutinya oleh 20 orang anggota kelompok masyarakat. Adapun jenis media tanam yang ada disekitar Desa Karangsari adalah tanah, pakis, kompos, dan humus. Dengan mengetahui cara pembuatan media tanam yang baik maka kelompok masyarakat yang terlibat akan mempunyai pengetahuan dan secara mandiri akan mengadakan media tanam guna keperluan pengadaan bibit ataupun untuk diperjualbelikan.
\end{abstract}

Kata Kunci: bibit; pemberdayaan; penyuluhan; persemaian

Submitted: 2021-08-09

Revised: 2021-10-26

Accepted: 2021-10-28

\section{Pendahuluan}

Kawasan Blok Karangsari Taman Nasional Gunung Ciremai (TNGC) merupakan salah satu dari zona rehabilitasi yang mempunyai tutupan lahan sebagian besar adalah tegakan Pinus merkusii. Berdasarkan hasil wawancara dengan masyarakat sejak Tahun 2014 kegiatan rehabilitasi pada blok ini telah dilakukan dengan menanam beberapa jenis tanaman rehabilitasi diantaranya beunying, walen, dan pulai. Untuk memenuhi kebutuhan rehabilitasi kawasan yaitu dengan ditaminya kembali maka diperlukan anakan pohon-pohon rehabilitasi yang berasal dari pembibitan (persemaian).

Dalam pembuatan bibit di persemaian, faktor lingkungan memegang peranan penting untuk mencapai pertumbuhan dan hasil yang maksimal. Hayati et al. (2012) menyatakan bahwa faktor lingkungan sangat berperan dalam proses pertumbuhan tanaman, media tumbuh adalah salah satu faktor lingkungan yang perlu dipertimbangkan. Selanjutnya juga dinyatakan bahwa media tanam yang baik biasanya digunakan campuran pasir, tanah, pupuk kandang. Penggunaan pasir sangat baik untuk perbaikan sifat fisik tanah terutama tanah liat.

Menurut Wira (2000) bahan-bahan untuk media tanam dapat dibuat dari bahan tunggal ataupun kombinasi dari beberapa bahan yang tetap berfungsi sebagai media tumbuh yang baik. Selanjutnya Osman (1996) menyatakan bahwa tanah dengan keadaan tekstur danstruktur yang baik sangat menunjang keberhasilan usaha pertanian, struktur tanah yang dikehendaki tanaman adalah struktur tanah yang gembur mempunyai ruang pori yang berisi air dan udara sehingga penyerapan unsure hara dapat berjalan optimal. Menurut Nyakpa dan Hasinah (1985) pupuk 
kandang dapat menambah unsur hara dalam tanah sebagai penyediaan humus yang dapat memperbaiki struktur tanah dan mendorong kehidupan jasad renik tanah. Arang sekam padi juga dapat digunakan sebagai bahan media tanam, menurut Rifai dan Subroto (1982) sekam padi merupakan hasil sampingan dari sisa-sisa pembakaran. Unsur hara yang terkandung dalan sekan padi relative cepat tersedia bagi tanaman dan dapat meningkatkan $\mathrm{pH}$ tanah. Selanjutnya menurut Prihmantoro dan Indriani (2003) arang sekam mempunyai sifat yang mudah mengikat air, tidak mudah menggumpal, harganya relatif murah, bahannya mudah didapat, ringan, steril dan mempunyai porositas yang baik.

Luaran yang dihasilkan dari kegiatan pengabdian kepada masyarakat ini adalah diperolehnya pengetahuan tentang jenis-jenis media tanam untuk kegiatan pembuatan bibit di persemaian. Luaran lainnya adalah publikasi jurnal. Rencana capaian luaran terbagi menjadi 2 tahap yaitu rencana jangka pendek dan jangka panjang. Target untuk jangka pendek bisa diselesaikan pada akhir Tahun 2020 yaitu tersedianya bibit yang berasal dari jenis-jenis media tanam yang berkualitas untuk kegiatan rehabilitasi kawasan. Target jangka panjangnya pada tahun 2021, masyarakat Desa Karangsari sudah melaksanakan produksi bibit tanaman rehabilitasi dan dapat dipasarkan. Dampak sosial dengan adanya pengenalan jenis-jenis media tanam yang melalui penyuluhan dan pelatihan adalah masyarakat yang terlibat akan mempunyai pengetahuan dan secara mandiri akan mengadakan media tanam guna keperluan pengadaan bibit ataupun untuk diperjualbelikan

\section{Metode}

Kegiatan ini dilakukan di Desa Karangsari Kecamatan Darma yang berbatasan langsung dengan Taman Nasional Gunung Ciremai (TNGC). Lama kegiatan sekitar 1 minggu, mulai dari persiapan hingga pelaksanaan. Kegiatan diawali dengan pembentukan tim, perumusan tujuan, persiapan, konsolidasi dan sosialisasi dengan mitra dan diakhiri dengan penyusunan laporan.

Pendekatan yang ditawarkan dalam kegiatan ini adalah melakukan melakukan pelatihan pengenalan jenis-jenis media tanam bagi pembuatan bibit di persemaian. Adapun tahapan yang akan dilaksanakan sebagai berikut:

1. Pelatihan tentang pengenalan jenis-jenis media tanam

Pelatihan akan dilakukan oleh dosen Fakultas Kehutanan Universitas Kuningan, sehingga diharapkan masyarakat mendapatkan pengetahuan tentang macam-macam media tanam.

2. Praktek pencampuran media tanam

Praktek pencampuran media tanam dilakukan oleh tim Fakultas Kehutanan kepada masyarakat dengan membuat bedengan pada persemaian kelompok tani.

ALUR PELAKSANAAN PELATIHAN PEMBUATAN MEDIA TANAM

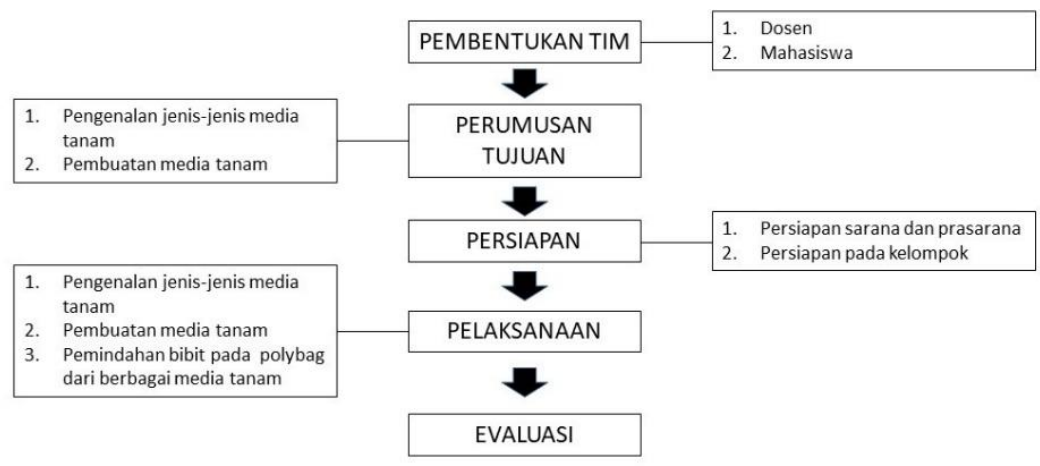

Gambar 1. Alur kegiatan pembuatan media tanaman 
Kegiatan ini melibatkan masyarakat sebagai mitra Fakultas Kehutanan Universitas Kuningan dengan harapan semua kegiatan dapat berjalan sesuai dengan tujuan yang telah disepakati. Bentuk keterlibatan masyarakat dalam kegiatan ini berupa pelibatan dalam menyiapkan alat dan bahan yang akan dipraktekkan. Kegiatan yang akan dilaksanakan ini merupakan kegiatan jangka panjang sehingga perlu dilakukan evaluasi pada setiap tahapan. Evaluasi program jangka pendek diharapkan masyarakat mampu membuat sirup pala sehingga evaluasi yang akan dilakukan adalah memantau setiap perkembangan yang terjadi di masyarakat dari hasil pelatihan. Target jangka panjangnya atau keberlanjutan program ini adalah masyarakat mampu memasarkan dan memperoleh perizinan produk hasil sehingga bisa meningkatkan penghasilan masyarakat.

\section{Hasil dan Pembahasan}

Tahap pertama dalam kegiatan pengabdian kepada masyarakat ini adal dengan dilakukan penyuluhan mengenai jenis-jenis media tanam yang terdapat di sekitar kawasan hutan yang dapat dimanfaatkan oleh masyarakat. Dalam kegiatan ini dihadiri oleh beberapa anggota dari kelompok masyarakat yang ada di Desa Karangsari Kecamatan Darma Kabupaten Kuningan. Kegiatan penyuluhan ini dilaksanakan beriringan dengan kegiatan lainnya. Komponen media tanam yang baik bagi pertumbuhan tanaman terdiri dari tanah, bahan organik, air dan udara. Komponen utama tanah untuk kehidupan tumbuhan yang optimalmenurut Buckman dan Brady (1982) terdiridari $50 \%$ ruang pori, $45 \%$ bahan mineral (anorganik) dan 5\% bahan organik.

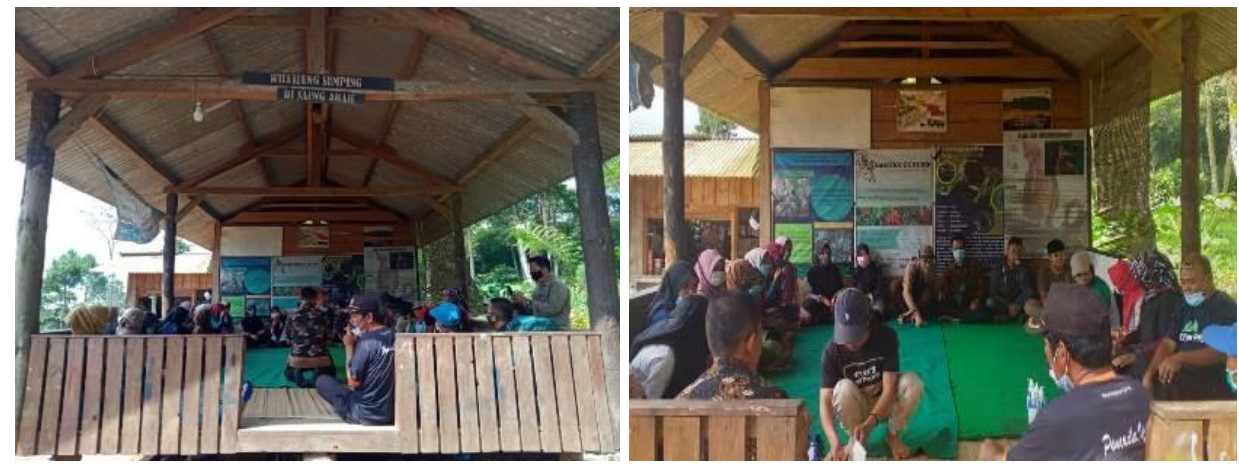

Gambar 2. Suasana kegiatan pelatihan

Media tanam yang dapat di dapatkan di sekitar kawasan Taman Nasional Gunung Ciremai adalah sebagai berikut :

1. Media tanam tanah.

Sebagai media tanam, tanah menyediakan faktor-faktor utama untuk pertumbuhan tanaman, yaitu unsur hara, air, dan udara dengan fungsinya sebagai media tunjangan mekanik akar dan suhu tanah. Semua faktor tersebut harus seimbang agar pertumbuhan tanaman baik dan berkelanjutan. Selain kandungan unsur makro dan mikro, tanah juga harus mengandung air. Daya simpan air pada jenis tanah tertentu akan berbeda, hal ini tergantung dari struktur tanahnya. Yang diperlukan dari media yang baik adalah jenis tanah yang dapat menyimpan air tetapi tidak berlebih, sesuai dengan kebutuhan tanaman dengan kondisi musim apapun. 

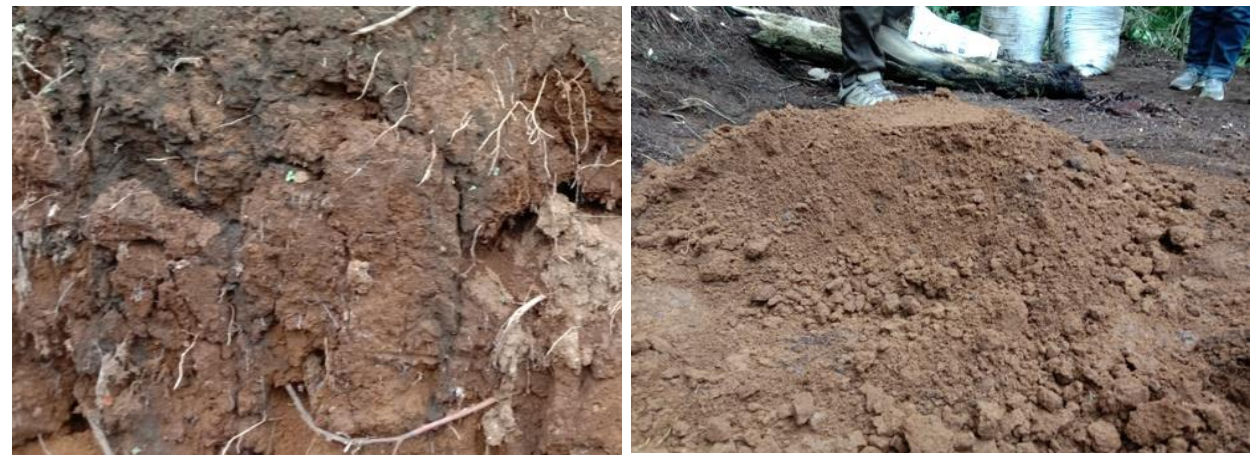

Gambar 3. Media tanam tanah

2. Media tanam batang pakis

Batang pakis bisa secara umum terbagi menjadi dua yakni pakis dengan warna hitam dan pakis coklat. Dari kedua jenis tanaman tersebut yang paling sering digunakan sebagai media tanam adalah pakis hitam. Batang pakis hitam biasa berasal dari tanaman pakis yang sudah berumur dan kering. Selain itu batang pakis juga mudah untuk dibentuk menjadi potonganpotongan kecil dan dikenal sebagai cacahan pakis. Keunggulan media tanam dari pakis adalah mudah untuk mengikat air, memiliki aerasi dan drainase yang baik. Selain itu media tanam ini memiliki tekstur lunak sehingga mudah ditembus oleh akar tanaman.
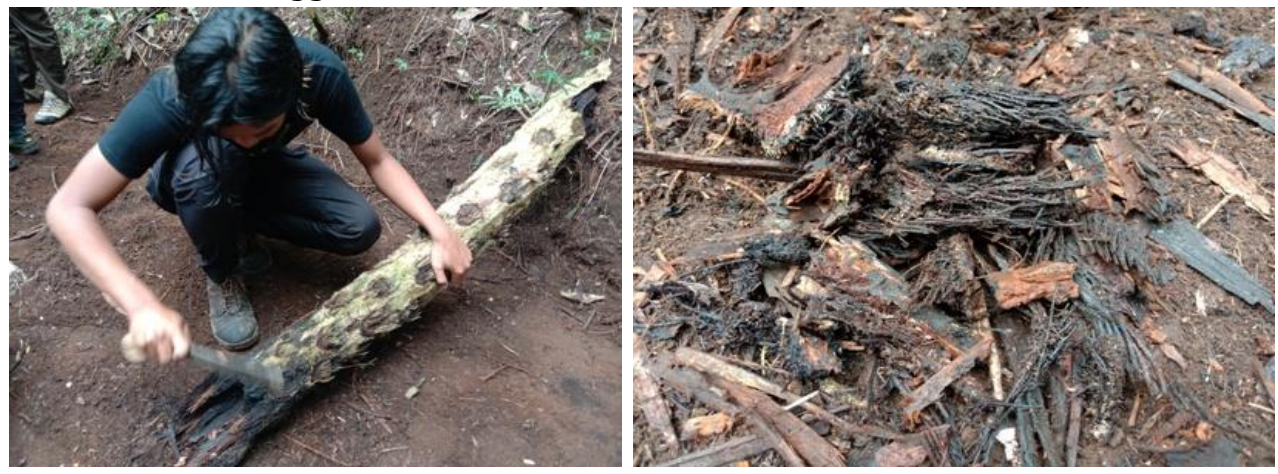

Gambar 4. Media tanam pakis

\section{Media tanam dari kompos}

Kompos merupakan media tanam organik yang terbuat dari proses tanaman atau limbah organik seperti sampah, daun, sekam, jerami, rumput. Kelebihan media tanam dari kompos yakni mampu mengembalikan kesuburan tanah melalui perbaikan sifat-sifat tanah, baik merupakan sifat kimiawi maupun biologis. Di samping itu kompos bisa menjadi fasilitator dalam penyerapan unsur nitrogen yang sangat diperlukan oleh tanaman. Kompos yang baik adalah yang terbuat dari tanaman yang telah mengalami pelapukan sempurna yang ditandai dengan perubahan warna menjadi hitam kecoklatan, tidak berbau serta memiliki kadar air rendah dan memiliki suhu ruang.
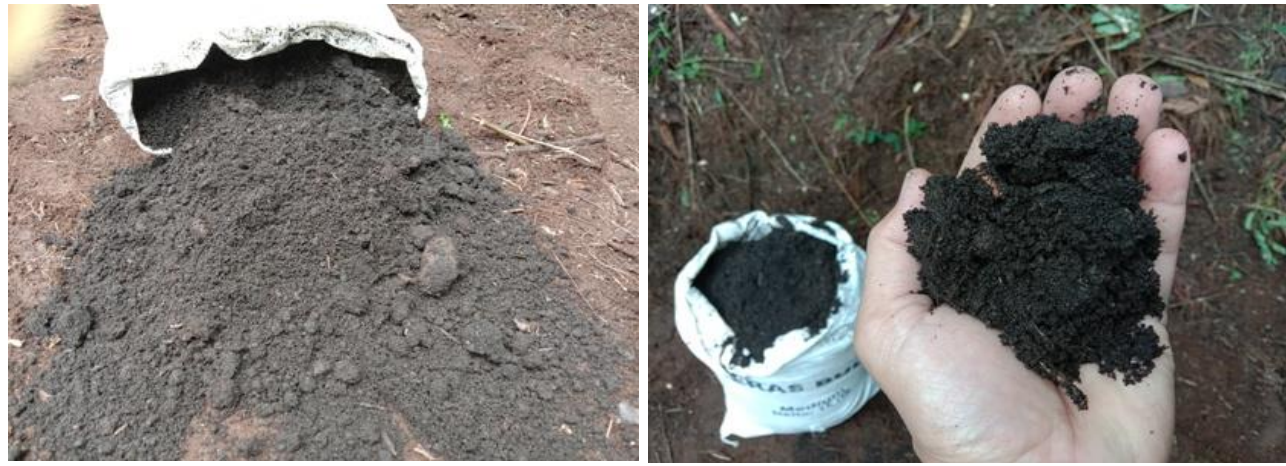

Gambar 5. Media tanam kompos 
4. Media tanam dari humus

Media tanam dari humus merupakan hasil dari pelapukan bahan organik serta jasad mikro dan sumber energi jasad mikro tersebut. Humus biasa terbentuk dari jaringan tubuh tumbuh-tumbuhan atau hewan yang telah mati. Humus sangat berperan dalam proses penggemburan tanah dan mempunyai kemampuan tukar ion yang tinggi sehingga bisa menyimpan unsur hara dengan baik. Humus sangat mudah untuk ditumbuhi jamur ketika terjadi perubahan suhu, kelembaban dan aerasi yang ekstrim. Humus juga memiliki tingkat porousitas yang rendah sehingga akar tanaman akan susah untuk menyerap air. Oleh karena itu penggunaan humus sebagai media tanam harus dikombinasikan dengan media tanam lain yang mempunyai porousitas tinggi misalnya tanah atau pasir.
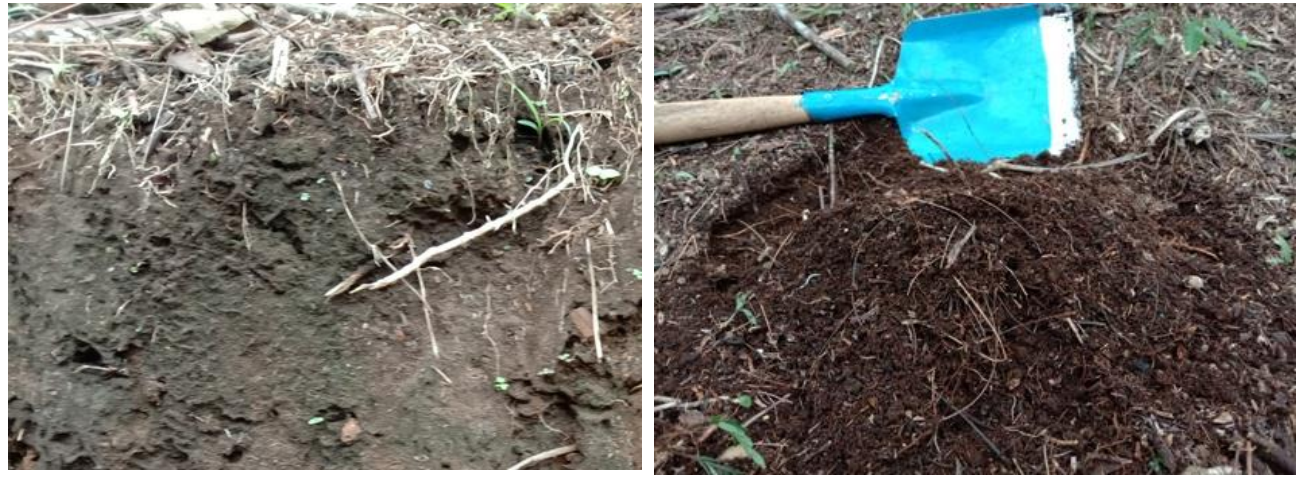

Gambar 6. Media tanam humus

Media tanam merupakan salah satu komponen penting dalam bercocok tanam. Media tanam yang dipakai untuk menanam tanaman harus sesuai sehingga tanaman bisa tumbuh dengan baik. Tapi terkadang menentukan media tanam yang tepat untuk jenis tanaman agar sesuai dengan habitat asalnya cukup sulit. Hal ini dikarenakan setiap daerah tempat tanaman tersebut berkembang berbeda-beda. Secara umum media tanam harus bisa menjaga kelembaban daerah sekitar akar tanaman serta menyediakan cukup udara dan unsur hara. Oleh karena itu jenis media tanam yang digunakan masing-masing daerah selalu berbeda-beda. Di Asia tenggara misalnya sejak tahun 1940 mengunakan media tanam dari pecahan batu bata, sabut kelapa, arang dan batang pakis. Media tanam tersebut bisa digunakan secara tunggal ataupun dikombinasikan antara bahan satu dengan yang lainnya.
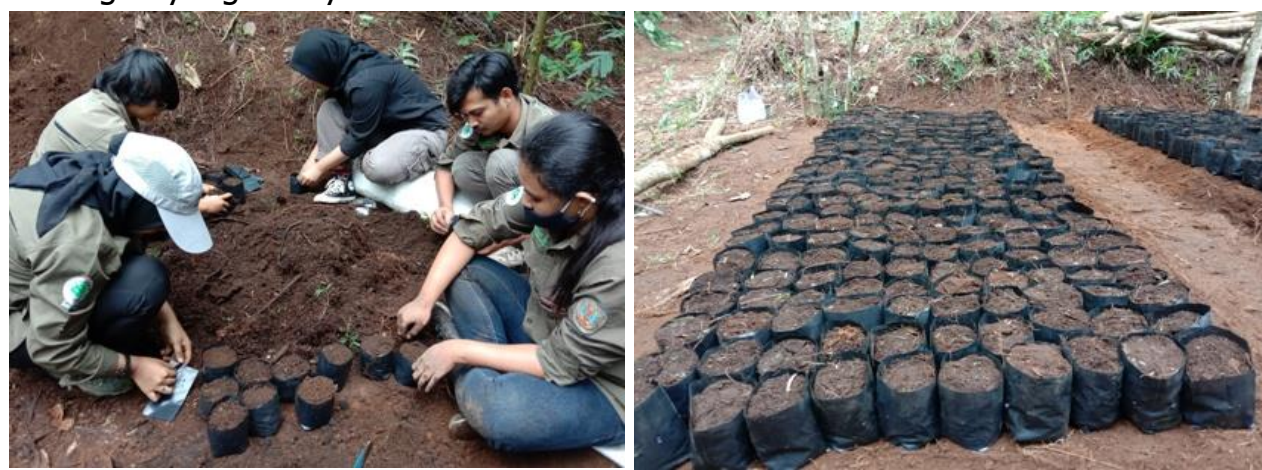

Gambar 7. Pembuatan media tanam 


\section{Kesimpulan}

Penyuluhan pengenalan dan pembuatan media tanam mendapat respon yang cukup baik dari kelompok masyarakat Desa Karangsari Kecamatan Darma. Jenis-jenis media tanam yang berada disekitar desa adalah tanah, pakis, kompos, dan humus. Dengan adanya kegiatan ini pengetahuan masyarakat bertambah dan kebutuhan akan bibit tanaman rehabilitasi dikemudian hari akan tercukupi.

\section{Daftar Pustaka}

Buckman, H dan Brady. (1982). Ilmu Tanah. PT Bhratara Karya Aksara. Jakarta

Hayati E, Sabaruddin dan Rahmawati. (2012). Pengaruh Jumlah Mata Tunas Dan Komposisi Media Tanam Terhadap Pertumbuhan Setek Tanaman Jarak Pagar (Jatropha curcas L.) Jurnal Agrista 16(3), 129-134

Nyakpa M.Y. \& Hasinah HAR, (1985). Pupuk dan Pemupukan. Fakultas Pertanian Unsyiah. Darussalam Banda Aceh.

Prihmantoro \& Indriani. (2003). Pengaruh Macam Media dan Intensitas Pemupukan Terhadap Pertumbuhan Bibit Tanaman Anthurium Gelombang Cinta (Anthurium plowmanii). Fakultas Pertanian universitas Sebelas Maret. Surakarta

Rifai, B \& Soebroto S.R, (1982). IImu Memupuk II. CV. Yasa Guna, Jakarta

Wira. N.J. (2000). Pengaruh Campuran Bahan Organik Terhadap Pertumbuhan dan Hasil Tanaman Seledri. (Skripsi). Fakultas Pertanian. Universitas Mataram.149h. 